\title{
Evaluation of Jordanian isolates of Beauveria bassiana (Balsamo) Vuillemin and their interaction with essential plant oils when combined for the two spotted spider mite, Tetranychus urticae Koch control
}

\author{
M. S. Al-alawi \\ Faculty of Agricultural Technology, Al-Balqa' Applied University, Assalt, 19117, Jordan
}

Correspondence Author: M. S. Al-alawi Faculty of Agricultural Technology, Al-Balqa' Applied University, Assalt, 19117, Jordan E-mail: m_mazrawi@yahoo.com

Received date: 20 July 2019, Accepted date: 15 September 2019, Online date: 30 September 2019

Copyright: (C) 2019 M. S. Al-alawi. This is an open-access article distributed under the terms of the Creative Commons Attribution License, which permits unrestricted use, distribution, and reproduction in any medium, provided the original author and source are credited.

\begin{abstract}
The two spotted spider mite is a destructive pest for a vast array of horticultural crops. Reliance on chemical acaricides for its control resulted in resistance developmental and control failure. A more sustainable approach for the mite control might involve the use of microbial and botanical pesticides. The current study evaluated the virulence of 6 Jordanian isolates in addition to a commercial isolate of Beauveria bassiana either alone or combined with sub-lethal doses of essential plant oils for effective mite control. A bioassay was conducted in the laboratory against the deutonymphs and the adults of the two spotted spider mite to identify the most virulent isolates and the most potent oils before their combined application. Results showed that combining pine oil or rosemary oil with $B$. bassiana always resulted in higher mortality than either of them alone. The mortality from the combined application of $B$. bassiana with pine oil was $87 \%$. The interaction between these two oils and $B$. bassiana was additive except for the combination of pine oil with isolate BAU016 which was synergistic. No antagonistic interaction was detected between the effective oils and the most virulent fungal isolates. These findings indicate that $B$. bassiana can be used with sub-lethal doses of pine or rosemary oils for effective and sustainable control of the two spotted spider mite with reduced reliance on chemical acaricides. Reduction in acaricidal applications would bring about the benefits of decreased resistance development, human health hazards and environmental contamination.
\end{abstract}

Keywords: Beauveria bassiana, Tetranychus urticae, essential oils, interaction

\section{INTRODUCTION}

Spider mites from the family Tetranychidae are major pests for many horticultural crops in the tropical and subtropical parts of the world. The two spotted spider mite, Tetranychus urticae Koch is considered the most destructive mite species within this family. This mite is highly polyphagous as it is reported to infest more than 150 plants whether they are vegetables, fruit trees and ornamentals [1]. In addition to the wide host range, the two spotted spider mite has a remarkably high reproductive capacity. Reproductive performance is highly dependent on the crop or even the variety of the crop and the environmental conditions particularly temperatures $[2,3]$. On eggplants at $25^{\circ} \mathrm{C}$, the females laid between $14-60$ eggs with a hatch rate ranging from 59 $83 \%$ [4]. Increasing the temperature decreased the development time of the $T$. urticae were it took the mite $16.23 \mathrm{~d}$ to develop to adults at $15^{\circ} \mathrm{C}$ but only $6.5 \mathrm{~d}$ to complete development at $35^{\circ} \mathrm{C}$ [5]. The intrinsic rate of natural increase, which is a measure of population growth, for T. urticae on soybean reached 0.292 females/female/day [6]. Although biological control was developed for the control of many spider mite species including T. urticae, chemical acaricides are still the main control method in the tropical and subtropical parts of the world. Growers in Jordan, as well as many Mediterranean countries, still rely heavily on the application of these chemicals. The key commercial biological control agents used in the temperate area, the predatory mite Phytoseiulus persimilis (Athias-Henriot) requires temperatures around $20^{\circ} \mathrm{C}$ for effective control. The predatory mite is ineffective at temperatures exceeding $30^{\circ} \mathrm{C}$ [7] which are common in the tropical areas. Total reliance on chemicals for $T$. urticae control coupled with the high reproductive rate led to the development of resistance to many well-known acaricides [8]. In addition to resistance development, pesticides are considered hazardous to human and the environment and their applications should be minimized as much as possible.One of the alternatives to chemical acaricides might be microbial control agents such as entomopathogenic fungi. One of the most promising entomopathogenic fungal species for the control of insects and mite is 
Beauveria bassiana (Balsamo) Vuillemin. B. bassiana was reported to naturally infect T. urticae in the field [9]. The fungus was also evaluated against $T$. urticae in the laboratory and found to be highly virulent causing more than 80\% mortality [10]. Field and greenhouse assessments were also conducted to evaluate $B$. bassiana against $T$. urticae with encouraging results. In one of the semi-field studies on chrysanthemum, the application of $B$. bassiana achieved better control for $T$. urticae than spraying a commercial acaricide [11].Another promising alternative for eco-friendly $T$. urticae management is the use of plant extracts, particularly, essential oils. In a screening study, 53 essential oils were tested against T. urticae as fumigants. The most efficacious oils were caraway seed, eucalyptus, citronella, lemon, pennyroyal, and peppermint causing high mortality to the mite [12]. Like entomopathogenic fungi, essential oils are regarded safer and environmentally benign alternatives to pesticides.

Given the potential of B. bassiana and plant essential oils as promising alternatives for $T$. urticae management, the current study was carried out to evaluate their combined use against this economically destructive pest. Developing management tactics based on $B$. bassiana and essential oils would bring out the benefits of reduced reliance on chemical acaricides in favor of human safe and environmentally friendly pest control methods.

\section{MATERIALS AND METHODS}

\section{Experimental materials}

Six $B$. bassiana isolates from Jordan in addition to the commercially available isolate GHA (BotaniGard®, Bio Works, USA) were evaluated against $T$. urticae. These isolates have previously shown high insecticidal activity against the green peach aphid, Myzus persicae (sultzar) [13]. They were isolated using the Galleria baiting method [14] from soil samples collected from different areas in Jordan. The isolates were cultured for 2 week in the dark at $24 \pm 2^{\circ} \mathrm{C}$ on B. bassiana selective medium consisting of Sabouraud's dextrose agar (SDA) amended with $1 \% \mathrm{wt} / \mathrm{v}$ yeast extract (SDAY), $0.55 \% \mathrm{wt} / \mathrm{v}$ Dodine and $0.005 \%$ wt/v chlortetracycline [15]. The fungal conidia were harvested and then stored as dry conidia in a refrigerator at $4{ }^{\circ} \mathrm{C}$. Shortly before the bioassay, the number of conidia per unit weight of each isolate was determined by suspending six $0.1 \mathrm{~g}$ samples taken at random in $100 \mathrm{ml}$ sterile distilled water and $0.1 \% \mathrm{v} / \mathrm{v}$ Tween 80 and agitated on a rotary shaker at $125 \mathrm{rpm}$ for $3 \mathrm{~h}$. After agitation, number of conidia was determined using a haemacytometer. Also, viability of B. bassiana conidia was checked by adding $200 \mu \mathrm{l}$ of each conidial suspension to $2 \mathrm{ml}$ of Sabouraud's dextrose broth amended with 1\% wt/v yeast extract (SDY) and $0.1 \% \mathrm{v} / \mathrm{v}$ Tween 80 . After incubation for $24 \mathrm{hr}$. at $24^{\circ} \mathrm{C}$ in darkness germination was assessed by counting $100 \mathrm{spores}$ in four different fields of view of a haemacytometer (total of 400 spores). To prepare the fungal isolates for the bioassay, the conidial suspension for each tested isolate was prepared by suspending the dry conidia in sterile distilled water amended with $0.1 \%$ Tween 80 to a concentration of $1 \times 10^{7}$ conidia $/ \mathrm{ml}$.

A field population of T. urticae was collected from cucumber plants (Cucumis sativus L.) grown in a plastic house in Jordan Valley. The mites were cultured on caster bean plants (Ricinus communis L.) grown in $15 \mathrm{~cm}$ diameter pots. To obtain different life stages of $T$. urticae, caster bean plants were placed within the mite culture for 24 hours. When eggs were observed on the plant leaves, the infested plants were then kept in a greenhouse at $24^{\circ} \mathrm{C} \pm 5$ and a natural daylight where $T$. urticae eggs were allowed to develop for the required life stage.

Six plant essential oils were included in the current study. They were cinnamon, eucalyptol, fir, pine, thyme and rosemary oils. The tested oils were supplied from the manufacturer (Sigma-Aldrich, EU) as pure oils with at least 95\% purity. To prepare the oils for the bioassay, they were mixed with sterile distilled water amended with $1.0 \%$ Tween 80 to a concentration of $10.0 \%$ wt/wt.

\section{Bioassay with B. bassiana and essential oils}

The bioassay with $B$. bassiana isolates and the essential oils was conducted using caster bean leaf discs $3 \mathrm{~cm}$ in diameter. The discs were removed from mite clean plants and placed in the center of $90 \mathrm{~mm}$ sterile Petri plates filled with water agar. To prevent the escape of the mites, a ditch $4 \mathrm{~mm}$ in width was cut off a round the leaf discs and removed from the agar lining and filled with sterile distilled water. Either $10 \mathrm{~T}$. urticae adults or deutonymphs were placed on the leaf discs using fine hair brush and then left for $2 \mathrm{hr}$. to settle down. Then, the Petri plates with the leaf discs and mite were sprayed by the either a $B$. bassiana isolate or an essential using Potter spray tower (Burckard Scientific, UK). After treatment, the plates were incubated at $24^{\circ} \mathrm{C} \pm 2$ and a $16 \mathrm{hr}$ photoperiod and T. urticae mortality was recorded on 5th day post application. T. urticae were considered dead if they did not move after probing with a fine hair brush or when mycosis was visible on the dead cadavers in case of the fungal treatment. The bioassay included a negative control which was sterile distilled water with $1.0 \%$ Tween 80 and a positive control which was the acaricide, Abamectin 1.8\% EC. There were three plates for each treatment and the controls and the whole bioassay was repeated twice so that there were 6 replicates for each treatment. To test the combined effect of the $B$. bassiana and essential oils, the three most virulent isolates and the three most toxic oils were evaluated against the adult stage of $T$. urticae as above except that oils were used at a lowered concentration of $1.0 \% \mathrm{wt} / \mathrm{wt}$. Each fungal isolate was tested in combination with each oil giving 9 treatment combinations.

To evaluate the effect of the selected oils in the combination bioassay on the fungal isolates, percentage and speed of conidial germination was assessed for each treatment combination of fungal isolate and essential oil as above with the addition of the corresponding oil to a concentration of $1 \% \mathrm{wt} / \mathrm{wt}$ to the Sabouraud's dextrose broth medium. However, in case of speed of germination, counts for germinated conidia was assessed bihourly starting $12 \mathrm{hr}$. after inoculation and ending after $24 \mathrm{hr}$. The time required for $50 \%$ germination to occur $\left(\mathrm{TG}_{50}\right)$ was calculated. A control treatment of each fungal isolate without the combined oil was included in the test. There were 5 replicates for each isolate oil combination.

\section{Statistical analysis}

PROC univariate, residual analysis was conducted to test the assumptions of model for Analysis of Variances (ANOVA). When assumptions were not met, the data were transformed. Percentage mortality of T. urticae adults and deutonymphs were corrected 
using Abbott's formula (Abbott, 1925) then arcsine square-root transformed before subjecting to two ways ANOVA (PROC GLM) [17]. Means were separated using the Student-Newman-Keuls test (SNK) multiple range test. To determine the type of interaction (additive, synergistic or antagonistic) for the combined application of $B$. bassiana and essential oils, expected mortality for each combination of $B$. bassiana with essential oils was calculated with the formula $\mathrm{P}_{\mathrm{e}}=\mathrm{P}_{1}+\left(1-\mathrm{P}_{1}\right)\left(\mathrm{P}_{2}\right)$, where $\mathrm{P}_{\mathrm{e}}=$ expected mortality, $\mathrm{P}_{1}=$ mortality from $B$. bassiana, and $\mathrm{P}_{2}=$ mortality from essential oils [18]. Chi-square tests were performed to determine the type of interaction by comparing the expected and observed mortalities by various treatment combinations [19]. If the calculated chi-square value exceeded the tabular value, then it indicated either synergistic or antagonistic interaction. In contrast, if the tabular value exceeded calculated chi-square value, then it indicated an additive effect. Data on percentage of spore germination was subjected to one-was ANOVA while speeds of germination data were analyzed using Probit analysis. The type I error rate was set at 0.05 level for all tests. Data were back-transformed to their original scales for presentation in tables.

\section{RESULTS}

Analysis of variance for the data on the virulence of $B$. bassiana isolates against the deutonymphs and adults of $T$. urticae showed significant interaction $\left(F_{7,80}=10.5 \mathrm{Pr}<0.001\right)$ between the isolates and the developmental stages. This interaction indicated that simple effects which are the effect of isolates over each developmental stage should be examined. Moreover, there were significant differences due to the isolate effect $\left(F_{7,80}=94.2 \mathrm{Pr}<0.001\right)$ as well as the developmental stage effect $\left(F_{1,80}=\right.$ 125.2 $\mathrm{Pr}<0.001)$. The highest significant mortality resulted from treating deutonymphs with Abamectin. Among B. bassiana isolates, deutonymphs treated with the isolate BAU016 suffered the highest mortality which was not significantly different from BAU007 and GHA but significantly higher than the rest of the tested isolates (Table 1). Similarly, all the isolates resulted in mortalities of $T$. urticae adults that were significantly lower than Abamectin. Again, the highest mortality was achieved by BAU016 followed by BAU007, GHA and BAU4 with no significant differences among them. However, these four isolates resulted in mortalities significantly higher than BAU18, BAU019 and BAU31 (Table 1). The virulence of B. bassiana isolates differed depending on the developmental stage. Adults treated with all the isolates suffered significantly higher mortalities than deutonymphs except the isolate BAU018 (Table 1).

With regard to the effect of essential oils on $T$. urticae, there was significant interaction $\left(F_{6,70}=6.8 \operatorname{Pr}<0.001\right)$ between the type of oil and the developmental stage. This interaction indicated that simple effects which are the effect of oils over each developmental stage should be examined. However, there were significant differences due to the type of oil effect $\left(F_{6,70}=211.6\right.$ $\operatorname{Pr}<0.001)$ but no significant difference due to the developmental stage effect $\left(F_{1,70}=3.3 \operatorname{Pr}=0.07\right)$. Because no significant difference was found within the developmental stages, no further mean separation was conducted. Abamectin outperformed all the tested oils and caused significantly the highest mortality in the two developmental stages (Table 2). For deutonymphs, rosemary oil resulted in significantly the highest mortality among the oils. Pine and fir oils caused similar mortalities which were significantly higher than cinnamon, eucalyptus and thyme oils (Table 2). However, pine oil caused significantly the highest mortality for the adult stage. The second highest mortality resulted from rosemary oil which was significantly higher than fir oil which was third in causing mortality to adults. The mortality from fir oil was significantly higher than the mortality from than cinnamon, eucalyptus and thyme oils (Table 2).

Data analysis for the interaction between $B$. bassiana isolates and essential oils showed that all the effects were additive except for the combination of isolate BAU016 and pine oil. This combination resulted in a synergistic interaction were combining BAU016 with pine oil resulted in significantly higher mortality than the expected one (Table 3). This combination of Bau016 and pine oil resulted in the highest mortality among either the isolate alone, or the combination of the other isolates with the tested oils. However, there were no significant differences in mortality of T. urticae adults treated with BAU016 and pine oil, BAU007 and fir oil, GHA and pine oil, GHA and fir oil. Treatment with the oils alone resulted in mortalities significantly lower than either the fungal isolates alone, or the combination of the isolates with the oils (Table 3).

Results from the effect of combining essential oils with $B$. bassiana on conidial germination showed that pine and rosemary oils did not significantly reduced the germination percentages for the three tested isolates compared to the controls (Table 4). On the contrary, fir oil significantly reduced the germination for the three isolates compared with pine oil, rosemary oil and the controls. Moreover, no significant differences were found among the essential oils combinations or the control in speed of conidial germination (Table 4).

\section{DISCUSSION}

The current study investigated the potential of using the entomopathogenic fungus $B$. bassiana combined with essential plant oils for safe and effective management of the economically destructive mite species, $T$. urticae. Virulence of $B$. bassiana against $T$. urticae was previously reported by many workers [20]. Similarly, many essential oils were screened for their effectiveness against $T$. urticae [21]. However, very little is known about the interaction between essential oils and $B$. bassiana when combined for T. urticae management. B. bassiana possess characteristics that made it more favorable for development as a microbial pesticide compared to other entomopathogens. Unlike many entomopathogens such as bacteria and viruses, $B$. bassiana penetrates the host pest, whether it is an insect or mite, directly through the cuticle without the need to be ingested upon feeding on the plants [22]. This route of penetration is crucial for the control of pest such as T. urticae that feed on the host plant by sucking the plant sap because plant sap feeders are unlikely to ingest microbes through feeding. Moreover, B. bassiana has a wide host range attacking many economical pests, easily and inexpensively cultured on artificial media and has long shelf life [23].

The isolates of B. bassiana evaluated in the current study have shown insecticidal activity against the economically important insect pest, the green peach aphid [14]. This aphid is considered a damaging pest for greenhouse crops in Jordan and many tropical parts of the world. Usually vegetable crops grown in greenhouses and open fields in Jordan are infested with the aphid 
and T. urticae simultaneously. Application of B. bassiana to multiple pest infestation would bring about the benefits of reduced chemical applications, time, effort and cost to growers.

The virulence of $B$. bassiana against $T$. urticae prominently differed depending on the developmental stage. More virulence was observed against the adult mite compared to deutonymphs. Similar finding were reported when the commercial product Naturali$\mathrm{L}^{\circledR}$, which is based on B. bassiana, was evaluated against immature stages and adults of T. urticae [24]. They found that the lethal concentration value $\left(\mathrm{LC}_{50}\right)$ was 3184 conidia/ml for the juvenile stages and 1949 conidia for the adults [24]. The reduced susceptibility of $T$. urticae nymphs to $B$. bassiana might be attributed to the molting process. The first step in $B$. bassiana infection involves adherence of the infective propagules to the host cuticle followed by germination and penetration. If the cuticle of the host is shed by molting before penetration occurs, the infection process might be hindered. The reduced virule nce due to molting was previously related to susceptibility of different instars of the European corn borer to B .bassiana [25].

Essential plant oils are also viable alternatives to chemical pesticides. Their acaricidal activity against $T$. urticae has been previously documented but mainly as fumigant action. Essential oil vapors from Satureja hortensis L., Ocimum basilicum L. and Thymus vulgaris L. were tested for their toxicities against the nymphs and adults of T. urticae and S. hortensis was found to be the most effective [26]. In addition, the acaricidal activity of many plant essential oils against $T$. urticae was clearly demonstrated in many later reports [27, 28, 29]. Most of the essential oils evaluated in the current study were not previously challenged against $T$. urticae with the exception of rosemary oil [27]. Three of these tested showed strong acaricidal activity against the target pests and caused mortalities exceeding 50\%. These oils were rosemary, pine and fir oils. The acaricidal activity of rosemary oil was previously reported [27] but this might be the first report about the acaricidal activity of pine and fir oils. One possible drawback associated with the application of essential oils as sprays on plants against insects and mites is their phytotoxicity [27]. A major objective of the current study was to evaluate the interaction effect between sub-lethal doses of essential oils with B. bassiana. Such sub-lethal doses are unlikely to cause phytotoxicity. The oils were first screened for acaricidal activity at a concentration of $10.0 \% \mathrm{wt} / \mathrm{wt}$ to select the most potent oils. Then, a sub-lethal dose of $1.0 \% \mathrm{wt} / \mathrm{wt}$ from each oil was combined with $B$. bassiana to investigate the potential of synergism to the fungal virulence. Interaction between $B$. bassiana and chemical insecticides/acaricides was found when they were combined for control of T. urticae. An antagonistic interaction resulted from the combined effect of $B$. bassiana and triflumuron [24]. When used at sub-lethal doses, synergistic interaction was revealed with flufenoxuron and $B$. bassiana but additive interaction resulted from azadirachtin and $B$. bassiana [30]. More recently, a synergistic interaction was found by combining low doses of spirodiclofen with $B$. bassiana on beans and cucumber [31]. However, very little is known about the interaction between essential plant oils and $B$. bassiana if both used to control spider mites. This interaction was clearly demonstrated in the current study. Seven out of nine combinations of $B$. bassiana and oils resulted in $T$. urticae mortalities higher than the fungus alone. Combining pine oil with $B$. bassiana always resulted in higher mortalities than using the fungus alone with a synergistic interaction when used with isolate BAU016. Combining the same isolate with fir oil resulted in reduced mortality indicating that the interaction is dependent on the type of essential oil. The reduced mortality when combing $B$. bassiana and fir oil might be attributed to the adverse effect of the oil on the conidial germination. As shown by the results, fir oil reduced the germination percentage of B. bassiana conidia particularly, the isolate BAU016. On the other hand, pine and rosemary oils showed no adverse effect on the germination of all the tested isolate. No antagonistic interaction was detected when combining either of the oils with the fungal isolates.

\section{CONCLUSIONS}

The two spotted spider mite is one of the major pets of horticultural crops. The control of this mite species is challenging due to the high reproductive rate and the development of resistance to acaricides. There is a clear need to develop biopesticides that are compatible with Integrated Pest Management (IPM) programs and organic farming for spider mites control. Both entomopathogenic fungi such as $B$. bassiana and plant essential oils are possible alternatives for development as biopesticides against spider mites. Combined application of entomopathogenic fungi and essential oils is an attractive approach, because the fungus and chemical insecticide may act synergistically, thereby allowing the use of lower concentrations and decreasing reliance on chemical acaricides. This synergistic interaction was found when combining pine oil with the isolate BAU016. Therefore, combining pine and rosemary oils with $B$. bassiana enhanced the virulence of the fungus providing an effective way to control T. urticae while protecting human health and the environment.

Table 1: Mean percentage mortality \pm (S.E.) of $T$. urticae deutonymphs and adults treated with different $B$. bassiana isolates at a concentration $1 \mathrm{X} 107$ conidia $/ \mathrm{ml}$.

\begin{tabular}{|c|c|c|}
\hline \multirow{2}{*}{ B. bassiana isolate } & \multicolumn{2}{|c|}{$\boldsymbol{T}$. urticae developmental stage } \\
\cline { 2 - 3 } & Deutonymph & Adult \\
\hline Abamectin & $85 \mathrm{a} \pm(2.1)$ & $82 \mathrm{a} \pm(3.1)$ \\
\hline BAU016 & $55 \mathrm{~b}^{*} \pm(2.2)$ & $67 \mathrm{~b}^{*} \pm(4.8)$ \\
\hline BAU007 & $48 \mathrm{bc}^{*} \pm(3.1)$ & $60 \mathrm{~b}^{*} \pm(5.2)$ \\
\hline GHA & $47 \mathrm{bc}^{*} \pm(4.2)$ & $62 \mathrm{~b}^{*} \pm(4.8)$ \\
\hline BAU004 & $42 \mathrm{~cd}^{*} \pm(3.1)$ & $57 \mathrm{~b}^{*} \pm(3.3)$ \\
\hline BAU018 & $35 \mathrm{de} \pm(3.4)$ & $40 \mathrm{c} \pm(3.7)$ \\
\hline BAU019 & $30 \mathrm{de}^{*} \pm(2.6)$ & $43 \mathrm{c}^{*} \pm(4.9)$ \\
\hline BAU031 & $27 \mathrm{e}^{*} \pm(2.1)$ & $42 \mathrm{c}^{*} \pm(4.0)$ \\
\hline
\end{tabular}

Means within columns with different letters and means within rows with asterisks are significantly different at 0.05 level using

Student-Newman-Keuls test for within columns and t-test for within rows. 
Table 2: Mean percentage mortality \pm (S.E.) of $T$. urticae deutonymphs and adults treated with different essential plant oils at a concentration of $10.0 \% \mathrm{wt} / \mathrm{wt}$.

\begin{tabular}{|c|c|c|}
\hline \multirow{2}{*}{ Essential oil } & \multicolumn{2}{|c|}{ T. urticae developmental stage } \\
\cline { 2 - 3 } & Deutonymph & Adult \\
\hline Abamectin & $85 \mathrm{a} \pm(2.2)$ & $80 \mathrm{a} \pm(2.6)$ \\
\hline Rosemary & $68 \mathrm{~b} \pm(3.1)$ & $63 \mathrm{~b} \pm(2.3)$ \\
\hline Pine & $52 \mathrm{c} \pm(3.1)$ & $72 \mathrm{c} \pm(3.6)$ \\
\hline Fir & $50 \mathrm{c} \pm(2.6)$ & $52 \mathrm{~d} \pm(4.0)$ \\
\hline Cinnamon & $23 \mathrm{~d} \pm(2.2)$ & $17 \mathrm{f} \pm(2.1)$ \\
\hline Eucalyptus & $13 \mathrm{e} \pm(2.1)$ & $25 \mathrm{e} \pm(2.2)$ \\
\hline Thyme & $10 \mathrm{e} \pm(2.6)$ & $12 \mathrm{f} \pm(1.7)$ \\
\hline
\end{tabular}

Means within columns with different letters are significantly different at 0.05 level using Student-Newman-Keuls test.

Table 3: Percentage mortality and interaction effects between isolates of $B$. bassiana at a concentration of $1 \times 10^{7}$ conidia $/ \mathrm{ml}$ and essential oils at a concentration of $1.0 \% \mathrm{wt} / \mathrm{wt}$.

\begin{tabular}{|c|c|c|c|c|}
\hline Treatment combinations & $\begin{array}{c}\text { Observed } \\
\text { mortality }\end{array}$ & $\begin{array}{c}\text { Expected } \\
\text { mortality }\end{array}$ & $\chi^{\mathbf{2 b}}$ & Effect $^{\mathbf{c}}$ \\
\hline BAU016 & $67 \mathrm{~b}$ & ---- & ----- & Synergistic \\
\hline BAU016 + pine oil & $87 \mathrm{a}$ & 70 & 4.13 & Additive \\
\hline BAU016 + rosemary oil & $65 \mathrm{~b}$ & 71 & 0.51 & Additive \\
\hline BAU016 + fir oil & $58 \mathrm{~b}$ & 69 & 1.75 & Additive \\
\hline BAU007 & $60 \mathrm{~b}$ & ----- & 0.40 & Additive \\
\hline BAU007 + pine oil & $68 \mathrm{~b}$ & 63 & 0.06 & Additive \\
\hline BAU007 + rosemary oil & $67 \mathrm{~b}$ & 65 & 2.29 & ----- \\
\hline BAU007 + fir oil & $75 \mathrm{ab}$ & 63 & ----- & Additive \\
\hline GHA & $62 \mathrm{~b}$ & ----- & 0.06 & Additive \\
\hline GHA + pine oil & $75 \mathrm{ab}$ & 65 & 2.22 & Additive \\
\hline GHA + rosemary oil & $65 \mathrm{~b}$ & 67 & ----- & ---- \\
\hline GHA + fir oil & $9 \mathrm{c}$ & 65 & ----- & -- \\
\hline Pine oil & $12 \mathrm{c}$ & ----- & - \\
\hline
\end{tabular}

Means within columns with different letters are significantly different at 0.05 level using Student-Newman-Keuls test.

${ }^{a}$ Expected mortality $=$ mortality from $B$. bassiana $+(1-$ mortality from B. bassiana $)($ mortality from oil) (Lord, 2001).

${ }^{\mathrm{b}}$ Tabular $\chi 2=3.84, \mathrm{df}=1, \alpha=0.05$

${ }^{\mathrm{c}}$ Dashes represent no effect.

Table 4: Effect of essential oils on conidial germination of $B$. bassiana isolates

\begin{tabular}{|c|c|c|}
\hline B. bassiana and oil combinations & $\begin{array}{c}\text { Percentage germination } \pm \\
(\text { S.E. })^{\mathrm{a}}\end{array}$ & $\begin{array}{c}\text { Speed of conidial germination } \\
\mathbf{G T}_{50}{ }^{b}(\mathrm{hr})(95 \% \mathrm{CL})^{\mathrm{c}}\end{array}$ \\
\hline BAU007 & $96 \mathrm{a} \pm(1.2)$ & $14.2(13.2-15.1)$ \\
\hline BAU016 & $95 \mathrm{a} \pm(1.3)$ & $14.8(14.1-15.7)$ \\
\hline GHA & $95 \mathrm{a} \pm(1.7)$ & $15.1(14.0-16.1)$ \\
\hline BAU016+ pine oil & $92 \mathrm{a} \pm(2.0)$ & $15.3(14.2-16.4)$ \\
\hline BAU007 + rosemary oil & $92 \mathrm{a} \pm(1.4)$ & $14.7(13.8-15.6)$ \\
\hline BAU007+ pine oil & $91 \mathrm{a} \pm(1.2)$ & $15.4(14.5-16.4)$ \\
\hline BAU016 + rosemary oil & $91 \mathrm{a} \pm(1.2)$ & $14.4(13.6-15.3)$ \\
\hline GHA + rosemary oil & $90 \mathrm{a} \pm(1.6)$ & $14.0(13.0-14.9)$ \\
\hline GHA + pine oil & $88 \mathrm{a} \pm(1.8)$ & $15.2(14.1-16.1)$ \\
\hline GHA + fir oil & $75 b \pm(2.2)$ & $14.6(13.7-15.4)$ \\
\hline BAU007 + fir oil & $73 b \pm(2.1)$ & $13.9(12.9-14.8)$ \\
\hline BAU016 + fir oil & $67 \mathrm{c} \pm(2.6)$ & $14.8(13.8-15.6)$ \\
\hline
\end{tabular}

${ }^{\mathrm{a}}$ Means within column with different letters are significantly different at 0.05 level using Student-Newman-Keul test.

${ }^{\mathrm{b}} \mathrm{GT}_{50}$ : Time by which $50 \%$ of conidia had germinated.

${ }^{\mathrm{c}} \mathrm{GT}_{50}$ 's with overlapping $95 \%$ confidence limits $(95 \% \mathrm{CL})$ are not significantly different at 0.05 level.

\section{ACKNOWLEDGEMENTS}

The author thanks The Scientific Research Fund, Ministry of Higher Education and Scientific Research, Jordan, Grant number Z, B/1/06/2008 for providing support for fungal isolation, Prof. Mazen Ateyyat for providing the essential oils and Omar Abu Hassan for technical help. 
[1] Jeppson, L. R., H.H. Keifer and T.W. Baker, 1975. Mite injurious to economic plants. University of California Press, Berkeley, CA.

[2] Abukhashim, N.K. and M.L Luff, 1997. Effects of short exposure periods to low temperatures on the biology of Tetranychus urticae. Acarology 38(3): 255-263.

[3] Adango, E., A. Onzo, R. Hanna, P. Atachi and B. James, 2006. Comparative demography of the spider mite, Tetranychus ludeni, on two host plants in West Africa. Journal of Insect Science, 6(49): 1-9.

[4] Khanamani, M., Y. Fathipour, H. Hajiqanbar and A. Sedaratian, 2012. Reproductive performance and life expectancy of Tetranychus urticae (Acari: Tetranychidae) on seven eggplant cultivars. Journal of Crop Protection 1(1): 57-66.

[5] Praslicka, J. and J. Huszar, 2004. Influence of temperature and host plants on the development and fecundity of the spider mite Tetranychus urticae (Acarina: Tetranychidae). Plant Protection Science-UZPI, 40

[6] Razmjou, J., H. Tavakkoli and A. Fallahi, 2009. Effect of soybean cultivar on life history parameters of Tetranychus urticae Koch (Acari: Tetranychidae). Journal of Pest Science, 82(1):89-94.

[7] Skirvin, D. and J. Fenlon, 2003. Of mites and movement: the effects of plant connectedness and temperature on movement of Phytoseiulus persimilis. Biological Control 27: 242-250.

[8] Hoy, M.A., 2011. Agricultural acarology. Introduction to integrated mite management. CRC, Boca Raton.

[9] Wright, J. E. and F. G. Kennedy, 1996. A new biological product for control of major greenhouse pests. British Crop Protection Council, Farnham (UK).

[10] Tamai M.A., S. B. Alves, J. E. M. de Almeida and M. Faion, 2002. Evaluation of entomopathogenic fungi for control of Tetranychus urticae Koch (Acari: Tetranychidae). Arquivos do Instituto Biológico, 69:77-84

[11] Alves, S.B., M. A. Tamai and R. B. Lopes, 1998. Avaliação de Beauveria bassiana (Bals.) Vuill. para controle de Tetranychus urticae Koch em crisântemo. In: Abstracts 17th Brazil. congr entomol Rio de Janeiro, p 1068.

[12] Choi, W. I., S. G. Lee, H. M. Park and Y. J. Ahn, 2004. Toxicity of plant essential oils to Tetranychus urticae (Acari: Tetranychidae) and Phytoseiulus persimilis (Acari: Phytoseiidae). Journal of economic entomology, 97(2): 553-558.

[13] Al-alawi, M. S. and M. Obeidat, 2014. Selection of Beauveria bassiana (Balsamo) Vuillemin isolates for management of Myzus persicae (Sultzar)(Hom.: Aphidae) based on virulence and growth related characteristics. American Journal of Agricultural and Biological Sciences, 9(1): 94-100.

[14]Zimmermann G., 1986. The "Galleria bait method" for detection of entomopathogenic fungi in soil. Zeitschrift Angewandte Entomologie 102: 213-215.

[15] Chase A.R., L.S. Osborne and V. M. Ferguson, 1986. Selective isolation of the entomopathogenic fungi Beauveria bassiana and Metarhizium anisopliae from an artificial potting medium. Florida Entomologist, 69: 285-292.

[16] Abbott, W.S., 1925. A method of computing the effectiveness of an insecticide. Journal of Economic Entomology 18:265267.

[17] SAS, 2002. Institute SAS/STAT user's guide, version 9. SAS Institute, Cary

[18] Lord, J. C., 2001. Desiccant dusts synergize the effect of Beauveria bassiana (Hyphomycetes: Moniliales) on stored-grain beetles. Journal of Economic Entomology, 94(2): 367-372.

[19] Quintla E. D. and C. W. McCoy, 1998. Pathogenicity enhancement of Metarhizium anisopleae and Beauveria bassiana to first instars of Diaprepes abbreviatus (Coleoptera: Curculionidae) with sublethal doses of Imidacloprid. Environmental Entomology 26: 1173-1132.

[20] Maniania, N. K., D. M. Bugeme, V. W. Wekesa, Jr. I. Delalibera and M. Knapp, 2008. Role of entomopathogenic fungi in the control of Tetranychus evansi and Tetranychus urticae (Acari: Tetranychidae), pests of horticultural crops. Experimental and Applied Acarology, 46(4): 259-274.

[21] Isman, M.B., 2006. Botanical insecticides, deterrents, and repellents in modern agricultural and an increasingly regulated world. Annual Review of Entomology 51: 45-56

[22] Wraight, S.P., and R. I. Carruthers, 1999. Production, delivery, and use of mycoinsecticides for control of insect pests of field crops. In Methods in Biotechnology, Vol. 5: Biopesticides: Use and Delivery, Hall, F. R. and J. J. Menn, Eds., Humana Press, Totowa, NJ. Pp: 233-270.

[23] Hajek, A.E. and R.J. St Leger, 1994. Interaction between fungal pathogens and insects host. Annual Review of Entomology, 39: 293-322.

[24] Irigaray F. J. SC., V. Marco-Mancebon and I. Perez-Moreno, 2003. The entomopathogenic fungus Beauveria bassiana and its compatibility with trifumuron: effects on the two-spotted spider mite Tetranychus urticae. Biological Control 26:168173

[25]Feng, Z., R. I. Carruthers, D. W. Roberts and D. S. Robson, 1985. Age-specific dose-mortality effects of Beauveria bassiana (Deuteromycotina: Hyphomycetes) on the European corn borer, Ostrinia nubilalis (Lepidoptera: Pyralidae). Journal of invertebrate pathology, 46(3): 259-264.

[26] Aslan, I., H. Özbek, O. Çalmaşur and F. Şahin, 2004. Toxicity of essential oil vapours to two greenhouse pests, Tetranychus urticae Koch and Bemisia tabaci Genn. Industrial Crops and Products, 19(2): 167-173.

[27] Miresmailli, S. and M. B. Isman, 2006. Efficacy and persistence of rosemary oil as an acaricide against two spotted spider mite (Acari: Tetranychidae) on greenhouse tomato. Journal of Economic Entomology, 99(6): 2015-2023.

[28] Pontes, W. J., J. C. de Oliveira, C. A. Da Camara, A. C. Lopes, M. G. Gondim, J. V. De Oliveira and M. O. Schwartz, 2007. Composition and acaricidal activity of the Resin's essential oil of Protium bahianum Daly against two spotted spider mite (Tetranychus Urticae). Journal of Essential Oil Research, 19(4): 379-383.

[29] Cavalcanti, S. C. H., E. D. S. Niculau, A. F. Blank, C. A. G. Câmara, I. N. Araújo, P. B. Alves, 2010. Composition and acaricidal activity of Lippia sidoides essential oil against two-spotted spider mite (Tetranychus urticae Koch). Bioresource Technology, 101(2): 829-832. 
[30] Hernández, M. M., E. Martínez-Villar, C. Peace, I. Pérez-Moreno and V. Marco, 2012. Compatibility of the entomopathogenic fungus Beauveria bassiana with flufenoxuron and azadirachtin against Tetranychus urticae. Experimental and Applied Acarology, 58(4): 395-405.

[31] Seyed-Talebi, F. S., K. Kheradmand, R. Talaei-Hassanloui and K. Talebi-Jahromi, 2014. Synergistic effect of Beauveria bassiana and spirodiclofen on the two-spotted spider mite (Tetranychus urticae). Phytoparasitica, 1-8.. 